\title{
Plastics: Issues Challenges and Remediation
}

\author{
Vipin Koushal1, Raman Sharma ${ }^{1 *}$, Meenakshi Sharma², Ratika Sharma ${ }^{3}$ and Vivek Sharma ${ }^{1}$ \\ ${ }^{1}$ Department of Hospital Administration, Chandigarh, India \\ ${ }^{2}$ Senior Research fellow, School of Public health, PGIMER, Chandigarh, India \\ ${ }^{3}$ Department of Sociology, Panjab University, Chandigarh, India
}

\begin{abstract}
Plastics have become a vital asset for humanity. Though extensive research and new technologies have led to invent of newer and safer plastics, but drawbacks and challenges of plastics have never been resolved and impact is on the rise. Some of the major compounds (vinyl chloride, dioxins, and plasticizers) are causative factors of hormone-disruption, reproductive dysfunction, breast growth and testicular cancers. The harmful effects are also pronounced in newborns via mothers during pregnancy or young children exposed directly.

Recycling is one of the most convenient and easiest ways. Smarter sorting, energy efficient ways, developing smarter plastics and research to develop certain fungi and bacteria that hasten degradation of conventional plastics are some of the present era needs. Source reduction (Reduce and Reuse) can occur by altering the design, manufacture or reduced use of plastic products.

Biodegradable plastics are similar to conventional plastics, with the additional quality of being able to naturally decompose and break into natural and safe byproducts. Bioplastics, nature derived plastics, are derived from biological sources such as sugar cane, cellulose etc. and these either degrade in open air or are made to compost using fungi, bacteria or enzymes.

To conclude, it is not the plastics to blame, but it is the misuse of plastics. The present time need is to look for biodegradable measures and effective policies and their implementation.
\end{abstract}

Keywords: Plastics; Impact; Prevention

\section{Introduction}

Plastic is a kind of material that is commonly known and used in everyday life in many forms. It becomes an important part of every one's life. To define plastics at molecular level, it is a kind of organic polymer, which has molecules containing long carbon chains as their backbones with repeating units created through a process of polymerization [1]. The structure of these repeating units and types of atoms play the main role in determining the characteristics of the plastic. These long carbon chains are well packed together by entanglements and Van der Waals forces forming a strong, usually ductile solid material [2]. Also, additives are usually added when manufacturing of commercial plastics is carried on, in order to improve the strength, durability or grant the plastic specific characteristics. Many of the controversies associated with plastics are associated with the additives [3].

Plastics have become a vital asset for humanity, often providing functionality that cannot be easily or economically replaced by other materials. Plastic products have brought benefits to society in terms of economic activity, jobs and quality of life. Most plastics are robust and last for hundreds of years. They have replaced metals in the components of most manufactured goods, including for such products as computers, car parts and refrigerators, and in so doing have often made the products cheaper, lighter, safer, stronger. Plastics have taken over from paper, glass and cardboard in packaging, usually reducing cost and also providing better care of the items.

Plastics also play a very vital role in hospitals and medical field. Plastics are used on large scale in hospitals. The daily plastic waste generation includes disposable syringes, I.V sets, glucose bottles, disposable plastic aprons; B.T sets; catheters and cannulas etc. are disposed of on daily basis. Plastics may be easy and convenient for everyday use, but their negative impacts on our health cannot be overlooked. Due to its non-biodegradable nature, it keeps on piling in the environment and is creating tons of trash around the world. Ian Connacher, the director of the film "Addicted to Plastics," once said in an interview with GreenMuze: "I don't think the material is to blame. I think it is our misuse of the material as consumers, the ineffective recycling policies and lack of producer [2]. In coming times also, the applications of plastics definitely are expected to increase as more new products and plastics are developed to meet demands. The increased use and production of plastic in developing and emerging countries is a particular concern, as the sophistication of their waste management infrastructure may not be developing at an appropriate rate to deal with their increasing levels of plastic waste.

Generally, there are two kinds of commercial plastics, thermoplastic (reheated, melted, and molded into different shapes) and thermosetting plastics which degrade and turn into other substances if reheated after molding [4]. Today, there are many different types of plastics manufactured in the plastic industry. The table below summarizes names of all commonly used plastics and their applications (Table 1).

New technologies and products were found after extensive research made in the field of plastics. Earlier the drawbacks of plastics were not known. The plastics are usually non-biodegradable and remain as

*Corresponding author: Dr. Raman Sharma, Department of Hospital Administration, Government Medical College \& Hospital, Chandigarh - 160012 India, Tel: +91-9463595994; E-mail: drramansharmamha@rediffmail.com

Received December 30, 2013; Accepted February 03, 2014; Published February 10,2014

Citation: Koushal V, Sharma R, Sharma M, Sharma R, Sharma V (2014) Plastics: Issues Challenges and Remediation. Int J Waste Resources 4: 134. doi: $10.4172 / 2252-5211.1000134$

Copyright: $\odot 2014$ Koushal V, et al. This is an open-access article distributed under the terms of the Creative Commons Attribution License, which permits unrestricted use, distribution, and reproduction in any medium, provided the original author and source are credited. 
Citation: Koushal V, Sharma R, Sharma M, Sharma R, Sharma V (2014) Plastics: Issues Challenges and Remediation. Int J Waste Resources 4: 134 doi: $10.4172 / 2252-5211.1000134$

Page 2 of 6

\begin{tabular}{|l|l|}
\hline \multicolumn{1}{|c|}{ Polymer type } & \\
\hline Polyethylene Terephthalate & Fizzy drink and water bottles. Salad trays. \\
\hline High Density Polyethylene & Milk bottles, bleach, cleaners and most shampoo bottles. \\
\hline Polyvinyl Chloride & Pipes, fittings, window and door frames (rigid PVC). Thermal insulation (PVC foam) and automotive parts. \\
\hline Low Density Polyethylene & Carrier bags, bin liners and packaging films. \\
\hline Polypropylene & $\begin{array}{l}\text { Margarine tubs, microwaveable meal trays, also produced as fibres and filaments for carpets, wall coverings and vehicle } \\
\text { upholstery. }\end{array}$ \\
\hline Polystyrene & $\begin{array}{l}\text { Yoghurt pots, foam hamburger boxes and egg cartons, plastic cutlery, protective packaging for electronic goods and toys. } \\
\text { Insulating material in the building and construction industry. }\end{array}$ \\
\hline Unallocated References & polycarbonate which is often used in glazing for the aircraft industry \\
\hline
\end{tabular}

Table 1: Types of Plastics \& Common uses.

waste in the environment for a very long time, thereby posing risks to human health as well as the environment. In the long run, overuse of plastics and lack of proper recycling yields many undesirable effects on our health.

The nature of traditional plastics is the reason why they cannot be biodegraded. The carbon chains of traditional plastics are too long and too well packed for microorganisms to digest, but if they are broken into small pieces the microorganisms will be able to degrade them. However, the breakdown process is too long for most of the traditional plastics, if there is no any artificial processing before being thrown in a landfill is involved. Therefore, before the plastics degrade themselves naturally, more plastics will be manufactured, causing increasing plastic pollution around the world [5]. Hence, with plastics, it is a full circle of problems and challenges that need to be resolved.

\section{Impact}

\section{Impact on environment}

Plastic is one of the major toxic pollutants of present time. Being composed of toxic chemicals and most importantly a nonbiodegradable substance, plastic pollutes earth and leads to air pollution and water pollution. This also mixes with food chain effecting Environment Humans and animals. There is no safe way to dispose plastic waste and waste causes serious damage to environment during its production process, during its usage and during its disposal process.

Toxic chemicals release during manufacturing process is another significant source of the negative environmental impact of plastics. A whole host of carcinogenic, neurotoxic, and hormone-disruptive chemicals are standard ingredients and waste products of plastic production, and they inevitably find their way into our ecology through water, land, and air pollution. Some of the major compounds include vinyl chloride (in PVC), dioxins (in PVC), benzene (in polystyrene), phthalates and other plasticizers (in PVC and others), formaldehyde, and bisphenol-A, or BPA (in polycarbonate). Many of these are persistent organic pollutants (POPs) - some of the most damaging toxins on the planet, owing to a combination of their persistence in the environment and their high levels of toxicity; however, their unmitigated release into the environment affects all terrestrial and aquatic life with which they come into contact.

It is in the use phase that the benefits of plastics in durability and effectiveness are most evident. Though most plastics are benign in their intended use form, many release toxic gases in their in-place curing (such as spray foam) or by virtue of their formulation (as with PVC additives off-gassing during their use phase). Occupational exposure during installation, such as inhalation of dust while cutting plastic pipe or off-gassing vapors of curing products, is also a great concern for human health and the environment.
The disposal of plastics-the "grave" phase, is one of the leastrecognized and most highly problematic areas of plastic's ecological impact. Ironically, one of plastic's most desirable traits-its durability and resistance to decomposition-is also the source of one of its greatest liabilities when it comes to the disposal of plastics. Natural organisms have a very difficult time breaking down the synthetic chemical bonds in plastic, creating the tremendous problem of the material's persistence. A very small amount of total plastic production (less than $10 \%$ ) is effectively recycled; the remaining plastic is sent to landfills, where it is destined to remain entombed in limbo for hundreds of thousands of years, or to incinerators, where its toxic compounds are spewed throughout the atmosphere to be accumulated in biotic forms throughout the surrounding ecosystems.

Unfortunately, because of plastic's low density, it frequently migrates "downstream," blowing out of landfills and off garbage barges. In 1997, Captain Charles Moore discovered widespread plastic garbage contamination area, called a gyre, in the North Pacific Ocean. By 2005, the estimated area of contamination expanded to 10 million square miles. $90 \%$ of this garbage was determined to be plastic, and $80 \%$ was originally sourced from land, such as construction waste. It has been reported that there are six similar gyres across the planet's oceans, each laden with plastic refuse.

\section{Impact on humans}

The harmful effects of plastic on aquatic life are devastating, and accelerating. The impacts of plastic waste on our health and the environment are only just becoming apparent. Most of our knowledge is around plastic waste in the marine environment, although there is research that indicates that plastic waste in landfill and in badly managed recycling systems could be having an impact, mainly from the chemicals contained in plastic.

Ingestion of plastic occurs more frequently than entanglement. The MFSD has identified ingestion of waste as an indicator for monitoring environmental status. Ingestion of plastic waste has been documented in a number of species. For some species, almost all individuals contain ingested plastic [6], including sea birds, fish, turtles, mussels and mammals. Clearly different species ingest different types and sizes of plastic debris. Many animals mistake plastic waste for prey, for example, fish can confuse plastic pellets for plankton, birds may mistake pieces of plastic for cuttlefish or other prey $[7,8]$.

There are several chemicals within plastic material itself that have been added to give it certain properties such as Bisphenol A, phthalates and flame retardants. These all have known negative effects on human and animal health, mainly affecting the endocrine system. There are also toxic monomers, which have been linked to cancer and reproductive problems. The actual role of plastic waste in causing these health impacts is uncertain. This is partly because it is not clear 
what level of exposure is caused by plastic waste, and partly because the mechanisms by which the chemicals from plastic may have an impact on humans and animals are not fully established. The most likely pathway is through ingestion, after which chemicals could bio accumulate up the food chain, meaning that those at the top could be exposed to greater levels of chemicals [9].

Plastic waste also has the ability to attract contaminants, such as persistent organic pollutants (POPs). Plastic could potentially transport these chemicals to otherwise clean environments and, when ingested by wildlife, plastic could cause the transfer of chemicals into the organism's system. However, in some conditions plastic could potentially act as a sink for contaminants, making them less available to wildlife, particularly if they are buried on the seafloor. With their large surface area-to-volume ratio, micro plastics may have the capacity to make chemicals more available to wildlife and the environment in comparison to larger sized plastics. However, once ingested, micro plastics may pass through the digestive system more quickly than larger plastics, potentially providing less opportunity for chemicals to be absorbed into the circulatory system [9].

Unfortunately, the properties of plastic that make it so valuable also make its disposal problematic, such as its durability, light weight and low cost. In many cases plastics are thrown away after one use, especially packaging and sheeting, but because they are durable, they persist in the environment. If plastic reaches the sea, its low density means it tends to remain on the surface. Most types of plastic are not biodegradable. Some plastics are designed to be biodegradable and can be broken down in a controlled environment, such as landfill, but it is uncertain if this will occur under other conditions, especially in oceans where the temperature is colder [10]. Even if plastic does eventually biodegrade, it will temporarily break into smaller fragments, which then produce so-called 'microplastics'. These have a specific and significant set of impacts.

The harmful effects of chemicals additives in plastics are also pronounced in newborns via mothers exposed to these toxins during their pregnancy. The second vulnerable groups are young children exposed directly to these chemicals. Since many of these chemicals (BPA and phthalates) can cross the placenta, resulting in growth retardation and neurological harm. There are also evidences to suggest hormonal derangements and cancers in children [11].

\section{Impact of single use plastics}

The single use plastics (drinking water bottles/ packing food stuff) are another issue surrounding the toxicity. Phthalates and Bisphenol A (BPA) are the two most notorious toxin which leach from plastics into food or water and when these plastic wastes are discarded improperly, they often end up in water bodies where they continue to leach these harmful chemical for an very long time.

Phthalates have been found to deposit in the fatty tissues of the body, and also causative factors of human diseases like male reproductive dysfunction, breast growth and testicular cancers [12]. BPA is often found in the food grade plastic known as polycarbonates, used in hospital disposables, has been found to have an estrogenic side effect. It is found to have detrimental effects on human placental tissues leading to premature birth, intrauterine growth retardation, preeclampsia and still birth [13]. Studies have shown that BPA may also lead to insulin resistance and diabetes also [14].

\section{Indian Scenario}

Plastic waste is a major environmental and public health problem in Indian set up particularly in the urban areas [15]. Plastic shopping or carrier bags are one of the main sources of plastic waste in our country. Plastic bags of all sizes and colors dot the city's landscape due to the problems of misuse and overuse and littering in India. Besides this visual pollution, plastic bag wastes contribute to blockage of drains and gutters, are a threat to aquatic life when they find their way to water bodies, and can cause livestock deaths when the livestock consume them. Furthermore, when filled with rainwater, plastic bags become breeding grounds for mosquitoes, which cause malaria. We have become so accustomed to the ubiquitous presence of plastic that it is difficult to envision life when woods and metals were the primary materials used for consumer products. Plastic has become prevalent because it is inexpensive and it can be engineered with a wide range of properties. Plastics are strong but lightweight, resistant when degraded by chemicals, sunlight, and bacteria, and are thermally and electrically insulating. Plastics have become a critical material in the modern economy; the annual volume of plastics produced exceeds that volume of steel [15].

The kind of recycling practiced in India is quite different from what is practiced in the rest of the world, in that state of the art technologies are not employed here. The starting point is the sorting of plastic waste (based on colour, transparency, hardness, density and opacity of the scrap). The sorted waste is then sent to the granulators to obtain granules using with the traditional mechanical and grinding techniques. The converters use these granules to make finished plastic products. The majority of such units (granulators and convertors) are often located in slums, and function single machine extruding units. Scrap storage is done in the backyards, and washing is done in open drums. These activities are often termed as backyard recycling. The technologies used in these industries are also old and local [16]. Of the types of plastics recycled in India, PVC (polyvinyl chloride) accounts for $45 \%$, LDPE (low density polyethylene) for 25\%, HDPE (high density polyethylene) for $20 \%$, PP (polypropylene) for $7.6 \%$ and other polymers such as PS (polystyrene) for $2.4 \%$ [17].

This recycling is usually results in the down cycling of plastics into lower-quality products that have higher and more 4 leachable levels of toxic additives [18]. During recycling, the plastic scrap is cleaned to remove the dirt and foreign matter adhering to it. The wastewater generated used for this purpose is finally disposed of into open drains. This wastewater has high pollution load in terms of BOD, COD, and TSS [16].

The final stage in the life cycle of plastics is disposal. In India, there are three common ways of getting rid off plastics - by dumping them in landfills, by burning them in incinerators or by littering them. In the case of littering, plastic wastes fail to reach landfills or incinerators. It is the improper way of disposing plastics and is identified as the cause of manifold ecological problems. Incineration of plastic wastes also significantly reduces the volume of waste requiring disposal [19]. It is believed that the volume reduction brought about by incineration ranges from 80 to $95 \%$. But the burning of these chlorine-containing substances releases toxic heavy metals and emits noxious gasses like dioxins and furans. The latter two are two of the most toxic and poisonous substances on earth and can cause a variety of health problems [18]. 


\section{Preventive Measures}

\section{Recycling}

Among the existing solutions recycling is one of the most convenient and easiest ways. There are various ways to participate through government programs or programs run by environmental organizations. As consumers, the recycling only requires one easy step of putting plastic wastes in right bins for disposal. Separating the plastic waste from other waste will prevent plastics to be land filled and will allow it to be recycled with other plastics of the same kind.

Recycling techniques deals with the tones of plastic waste that is choking earth. So in addition to developing smarter plastics that takes the place of conventional plastics, there is emergent need to deal with the immense quantities of toxic wastes already out there and hurting humans and the environment. Smarter sorting of plastic Wastes, energy efficient ways of getting rid of the plasticizers and increasing the scale of this entire process is very vital to overcome this challenge. Recent reports of discovery of certain fungi and bacteria that hasten degradation of conventional plastics have received a lot of scientific attention. In this process, the byproducts of this natural way of decomposition are safe for the environment and there are no hidden adverse consequences of this approach.

\section{Reduced use of plastics}

Plastic pollution can be reduced by using less plastics products and switching to alternatives. Each year, an estimated 500 billion to 1 trillion plastic bags are consumed worldwide. That comes out to over one million per minute. Billions end up as litter each year or in landfills. Now focus on another important part of eco-friendly living: reduce your use of plastic.Source reduction (Reduce and Reuse) can occur by altering the design, manufacture, or use of plastic products and materials. For example, the weight of a 2-liter plastic soft drink bottle has been reduced from 68 grams to 51 grams since 1977, resulting in a 250 million pound decrease of plastic per year in the waste stream.

\section{Tips for safer, more sustainable use of plastics:}

- Beware of cling wraps especially for microwave use.

- Avoid plastic bottled water.

- Minimize the use of canned foods and canned drinks.

- Purchase baby bottles and sippy cups or glass options.

- Bring your own cloth bags to the grocery store or any store.

- Don't buy beverages bottles in plastic.

- Carry your own reusable steel or ceramic beverage container.

- Don't buy convenience foods packages in plastic.

- Buy bread from bakeries that package in paper.

- Buy laundry detergent in boxes, not liquid in plastic containers.

- Buy farm fresh eggs in reusable paper containers.

- Package your leftovers in corning ware.

- Store all your food in glass containers instead of plastic containers.

- Buy bulk cereal; bring your own paper bags.

- Compost your trash; reduce your use of plastic trash bags.

- Line small trash bins in your house with paper bags.
- Use cloth rags for clean up around the house.

- Use matches instead of plastic encased lighters.

- Use cloth napkins. They reduce your waste and use of plastic trash bags.

- Use baby bottles made of glass.

- Use rechargeable batteries to reduce buying batteries packaged in plastic.

- Make a compost heap to reduce your food waste and put it back into the earth.

- Use a reusable cloth bag to carry your lunch to work or school.

- Spread the word, tell people about the harmful chemicals in plastic and help reduce plastic use.

\section{Chemical decomposing}

Chemical decomposing is otherwise a very effective solution to plastic pollution, since the non-biodegradable property of plastic is the main cause of plastic pollution. However, no technology has been developed yet to set up an economical and effective large-scale plastic decomposing facility. But chemical decomposing is still a field that has a great potential to develop in the future.

There are mainly two ways to decompose conventional plastics. Decomposing plastics by microorganisms is one of them. Daniel Burd, a Canadian high school student, found out that there are three kinds of microorganisms in the earth from a landfill that can break down the molecules of plastic bags. However, since this is a relatively new discovery, it is not applied industrially yet. Its economical applicability still needs to be discussed, but according to Burd, this decomposing method is possible to be applied on an industrial scale. Another way to decompose plastics is by combustion. This is a relatively easy and inexpensive way compared to using microorganisms, however, odor and toxic gases produced during combustion is a big problem. Currently, some companies have already applied this method, and Wheelabrator Technologies Inc. is one of them. In

Wheelabrator's clean energy plants, waste are burned and heat generated from combustion is turned to electricity with emission air control [20]. These waste-to-energy plants not only handle municipal waste environmentally, but also provide electricity to households and businesses.

\section{Alternative solutions}

Biodegradable Plastics (BDP): This is one of the options to the conventional plastics. One of the common constituents of BDP is polyhydroxyalkanoate (PHA). The BDP are similar to conventional plastics in all aspects with the additional quality of being able to naturally decompose and break into natural and safe byproducts. Hence if all plastics in the city waste were biodegradable, it could simply be allowed to decompose along with the food and other non-recyclable but biodegradable articles like wet paper and cotton fibers [19].

Since the technologies to manufacture BDPs are relatively new and not widely prevalent, the production cost is higher. Therefore, further research in areas of more cost effective and energy efficient manufacturing methods for biodegradable plastics is the call of the hour [19]. The incorporation of BDP is a progressive approach to a greener, healthier, and a better environment. The progressive development of several biopolymers over the years has stirred the plastic industry. The induction of biodegradable plastics is a promising and progressive prospect and will greatly reduce the dependence on fossil fuels. At 
the present time, it is only an option over traditional plastics, but if it is to replace traditional plastics completely, people would have no other option but to use them. Incorporating biodegradable plastics in everyday use would not only take the pressure off fossil fuels but also encourage agricultural producers who are interested in exploring and developing the natural fiber processing industry. A lot of income from agriculture can be generated if biodegradable plastics can be made mainstream. Aside from the obvious economic and environmental benefits, biodegradable plastics are progressive from scientific point of view as well. In addition to being useful for everyday life purposes, biodegradable plastics also have a great scope to be used in medicinal field.

What sets biodegradable plastics one step ahead of conventional plastics is the fact that they can be manufactured by using renewable biomass instead of biofuels. This will be of huge advantage because as "renewable biomass", will include "agro-industrial" wastes that are not only cheap, but their conversion solves another problem by turning waste materials into useful products. This makes production of biodegradable plastics possible even in the countries that lack the scope for crop expansion. In return, they are being benefitted economically and ecologically. At present biodegradable polymer technology can only offer a limited range of materials. It is due to this limitation that biodegradable plastics have not been able to go mainstream yet.

Bioplastics: A bioplastic is a plastic that is made partly or wholly from polymers derived from biological sources such as sugar cane, potato starch or the cellulose from trees, straw and cotton. Some bioplastics degrade in the open air, others are made so that they compost in an industrial composting plant, aided by fungi, bacteria and enzymes. Others mimic the robustness and durability of conventional plastics such as polyethylene or PET.

Bioplastics - partly or wholly made from biological materials and not crude oil - represent an effective way of keeping the huge advantages of conventional plastics but mitigating their disadvantages. However, that does not imply that bioplastics can naturally decompose like biodegradable plastics. The prime benefit is that it gives some respite to our depleting petroleum reserves.

Hence, further research should focus on developing bioplastics that are both biodegradable and also energy efficient to produce. Recycling is almost always more energy efficient and releases less carbon dioxide than making a new product. One major problem with efforts to recycle bioplastics is that if they become mixed with petroplastics they can contaminate the whole batch.

Polymer Blended Bitumen Roads: The non-wetting property of plastics is also being implemented successfully in road construction business. Bitumen film is often stripped off the aggregates because of the penetration of water, which results in pothole formation. When polymer (plastic waste) is coated over aggregate, the coating reduces its affinity for water due to non-wetting nature of the polymer, thereby obstructing the penetration of water. Polymers also shows higher softening temperature, thereby reduce the bleeding of bitumen during the summers [21].

To get rid of plastic waste disposal problems, Central Pollution Control Board (CPCB) has taken initiative to use the plastic waste in manufacturing units through co processing. Co-processing refers to the use of plastic waste materials in industry process such as cement, lime or steel production and power stations or any other large combustion plants. Co-processing refers to substitution of primary fuel and raw material by waste. Waste material such as plastic waste act as alternative fuels and raw material (AFR). Thus these units save fossil fuel and raw material consumption, contributing the more eco-efficient production. After getting encouraging results CPCB has granted permission to many cement plants to co-process the hazardous and non-hazardous (including plastic) waste in their kilns after trial burns [21].

1. While some people are busy developing plastic substitutes, others are bent on making conventional thermoplastics biodegradable. By throwing in additives called Prodegradant concentrates (PDCs). PDCs are usually metal compounds, such as cobalt stearate or manganese stearate. They promote oxidation processes that break the plastic down into brittle, low-molecular-weight fragments. Microorganisms gobble up the fragments as they disintegrate, turning them into carbon dioxide, water and biomass, which reportedly contains no harmful residues. When added to polyethylene (the standard plastic bag material) at levels of 3\%, PDCs can promote nearly complete degradation; $95 \%$ of the plastic is in bacteria-friendly fragments within four weeks.

2. Researchers are revitalizing the idea of converting casein, the principal protein found in milk, into a biodegradable material that matches the stiffness and compressibility of polystyrene. The modern milk-based plastic doesn't crack as easily, thanks to that silicate skeleton, and they even made the stuff less toxic by substituting glyceraldehyde for formaldehyde during the process. Scientists have found a way make the protein less susceptible to cracking, thanks to a silicate clay called sodium montmorillonite.

3. Chicken feathers are composed almost entirely of keratin, a protein so tough that it can give strength and durability to plastics. It's found in hair and wool, hooves and horns -- and we can all appreciate how strong a horse's hoof can be without having the pleasure of being kicked by one. Researchers decided to tap into keratin's superstrong features by processing chicken feathers with methyl acrylate, a liquid found in nail polish. Ultimately, the keratin-based plastic proved to be substantially stronger and more resistant to tearing than other plastics made from agricultural sources, such as soy or starch, and scientists are clucking excitedly about chicken-feather plastic. After all, inexpensive, abundant chicken feathers are a renewable resource.

4. Next up is a promising new bioplastic, or biopolymer, called liquid wood. Biopolymers fake it; these materials look, feel and act just like plastic but, unlike petroleum-based plastic, they're biodegradable. This particular biopolymer comes from pulp-based lignin, a renewable resource.

5. The next three entries on this list are all biodegradable plastics called aliphatic polyesters. Overall, they aren't as versatile as aromatic polyesters such as polyethylene terephthalate (PET), which is commonly used to make water bottles. But since aromatic polyesters are completely resistant to microbial breakdown, a lot of time and effort is being pumped into finding viable alternatives in aliphatic polyesters. polycaprolactone (PCL), a synthetic aliphatic polyester that isn't made from renewable resources but does completely degrade after six weeks of composting.

6. Polyhydroxyalkanoate (PHA) polyesters, the two main members of which are Polyhydroxybutrate (PHB) and Polyhydroxyvalerate (PHV). These biodegradable plastics closely resemble man-made polypropylene. While they're still less flexible than petroleum-based plastics, you'll find them in packaging, plastic films and injectionmolded bottles.

\section{References}

1. http://www.merriam-webster.com/dictionary/polymer. 
Citation: Koushal V, Sharma R, Sharma M, Sharma R, Sharma V (2014) Plastics: Issues Challenges and Remediation. Int J Waste Resources 4: 134. doi: 10.4172/2252-5211.1000134

2. Greenmuze (2008) Addicted to plastics.

3. Elias HG (2005) Plastics, General Survey. Ullmann's Encyclopedia of Industrial Chemistry.

4. Callister WD, Rethwisch DG (2008) Fundamentals of Materials Science and Engineering: An Integrated Approach (3rdedn).

5. Li N, Mahat D, Park S (2009) Reduce Reuse and Replace: A Study on Solutions to Plastic Wastes. An Interactive Qualifying Project Submitted to the faculty of Worcester Polytechnic Institute.

6. Ryan PG, Moore CJ, Franeker JA, Moloney CL (2009) Monitoring the abundance of plastic debris in the marine environment. Philos Trans R Soc Lond $B$ Biol Sci B 364: 1999-2012.

7. Derraik JGB (2002) The pollution of the marine environment by plastic debris: a review. Marine Pollution Bulletin 44: 842-852.

8. Gregory MR (2009) Environmental implications of plastic debris in marine settings-entanglement ingestion smothering hangers-on hitch-hiking and alien invasions. Philos Trans R Soc Lond B Biol Sci. 364: 2013-2025.

9. Science for Environment Policy (2011) Plastic Waste: Ecological and Human Health Impacts. In-depth Reports.

10. Schuler K (2008) Smart Plastics Guide: Healthier Food Uses of Plastics. Minneapolis Minnesota.

11. Zaman T (2010) The Prevalence and Environmental Impact of Single Use Plastic Products.
12. Jobling S, Reynolds T, White R, Parker MG, Sumpter JP (1995) A variety of environmentally persistent chemicals including some phthalate plasticizers are weakly estrogenic. Environ Health Perspect 103: 582-587.

13. Benachour N, Aris A (2009) Toxic effects of low doses of Bisphenol-A on human placental cells. Toxicol Appl Pharmacol 241: 322-328.

14. Magdalena AP, Morimoto S, Ripoll C, Fuentes E, Nadal A (2006) The estrogenic effect of bisphenol $A$ disrupts pancreatic beta-cell function in vivo and induces insulin resistance. Environ Health Perspect 114: 106-112.

15. Tammemagi HY (1999) The Waste Crisis: Landfills Incinerators and the Search for a Sustainable Future. Oxford University Press New York.

16. Narayan P (2001) Analyzing Plastic Waste Management in India: Case study of Polybags and PET bottles|| published by IIIEE. Lund University Sweden 24-25.

17. Shah P (2001) The Plastic Devil: Ecological Menace.

18. Chaturvedi $B$ (2002) The source of this information is a press release of No Plastics in the Environment (Nope) Imports Versus Surplus: A Glut of Plastics in India Today. Chintan Environmental Organization.

19. Begum Z (2010) Plastics and environment. Dissemination Paper for the Ministry of Environment and Forest. Government of India.

20. Wheelabrator Technologies Inc (2009) About Us

21. Material on Plastic Waste Management (2012) Central Pollution Control Board India. 